\title{
Cytomixis and the Loss of Chromosomes in Meiotic and Somatic Cells of Gossypium
}

\author{
Patricia Sarvella ${ }^{1}$
}

North Carolina State College, Raleigh, N. C., U.S.A.

Received June 16, 1957

Passage of chromatin from the nucleus of one pollen mother cell (PMC) into the cytoplasm of an adjacent PMC of Oenothera gigas was named "cytomyxis" by Gates in 1911. He attributed this transfer of chromatin material to an extrusion, but it will be referred to here simply as a movement of chromatin. This process had already been described as early as 1901 by Körnicke in the PMC's of Crocus vernus and by Miehe in the epidermal layers of various other monocotyledonous plants. Since 1901, cytomixis, as it is now spelled, has been reported in a wide range of genera and species reviewed by Maheshwari (1950) and Tischler (1951). Additional examples of cytomixis were described or illustrated in hemp (Breslavetz 1935), several other angiosperms (Cooper 1952), Secale cereale $\times$ Agropyrum intermedium (Gaul 1954), Salvia (Linnert 1955), Primula and Cyclamen (Nybom 1946), Aegilops $\times$ wheat hybrids (Percival 1930), wheat (Powers 1932), Solanum quitöense and Nicotiana tabacum (Sarvella unpublished).

Chromatin movement may affect a row or series of cells simultaneously. Gates (1911) reported that cytomixis took place at the same time in all the PMC's of a given anther and always in the same direction in all the cells. However, Kattermann (1933) found this movement to be non-uniform in direction and the contents of one cell could often be seen in two or three neighboring cells. The nucleolus of a cell undergoing cytomixis may remain behind (Gates 1911) or pass piecemeal into the cytoplasm of a neighboring cell (Youngman 1931). Generally, cytomixis has been reported to occur from leptotene to metaphase I (Kihara and Lilienfeld 1934), although cases have been seen as late as second telophase (Stebbins 1932).

Deviations of chromosome numbers from the normal have been attributed to cytomixis. Woodworth (1929) explained abnormal numbers in metaphase II plates of Corylus as due to cytomictic migrations or chromosome fusion. Cytomixis appeared to be responsible for the occurrence of several PMC's with about thirty-five univalents in the cross of Aegilops ovata $(n=14) \times$ Triticum monococcum $(n=7)$ (Percival 1930). Yamashita (1937) thought

1 Contribution from the Field Crops Department, North Carolina Agricultural Experiment Station, Raleigh, N. C. Published with approval of the Director of Research as Paper No. 802 of the Journal Series; supported in part by Project S-1 of the Research and Marketing Act of 1946. Aided by a grant (G720) from the National Science Foundation. 
nuclear migrations were the cause of groups of Triticum cells with reduced chromosome numbers. PMC's with reduced chromosome numbers were believed by Kihara and Lilienfeld (1934) to originate from cytomixis. They also felt that cytomixis could be the cause of polyploid series and cells with aberrant chromosome numbers or with chromosome fragments.

Binucleate cells were also thought to originate from cytomixis (Nandi 1937). This was especially striking in the haploids of Nicotiana tabacum in which Ruttle (1928) saw no anthers with binucleate PMC's that did not also have cytomixis, and a binucleate PMC was observed next to an enucleate cell.

Cytomixis was described in cotton root tips by Jacob (1941). Youngman (1931) observed cytomixis in the PMC's of the closely related genus Thespesia, and stated that chromatin extrusion "would appear to be also a general one [phenomenon] in the nearly related genus Gossypium...". A binucleate PMC was reported by Iyengar (1943) in a backcrossed plant of $G$. hirsutum $\times$ $G$. herbaceum although no explanation was given for its origin.

Abnormal chromosome numbers have also been reported in Gossypium. One PMC in the backcrossed progeny of $G$. arboreum $\times$ herbaceum to $G$. arboreum had ten bivalents instead of the expected thirteen (Gerstel 1955), and in a hexaploid hybrid (Brown 1951), nine plates out of fifty were aberrant-seven plates having less and two more than the hexaploid number. Brown (1947) found several branches on a plant resulting from a Gossypium $\times$ Hibiscus cross in which there was a spontaneous reduction of chromosome numbers from nearly a hundred chromosomes to seventy-seven. Menzel and Brown (1952) and Menzel (1952) explained the occurrence of mosaic spots in the leaves and petals of amphiploid hybrids, and a reduced chromosome number in a tri-species hybrid as resulting from atypical segregational mitoses.

The present paper is a report on various types of abnormalities that were encountered during a cytogenetic study of the pollen mother cells of some Gossypium species and hybrids (Sarvella 1957) and an attempt to explain the cause of these abnormalities.

\section{Materials and methods}

Cytological studies were made in both the diploid species $G$. arboreum and the tetraploid species $G$. hirsutum. Also, the three hybrids involving the tetraploid species G. hirsutum, G. barbadense, and G. tomentosum were examined. Several synthesized hexaploid and tetraploid interspecific hybrids were studied: $6 n$ (G. hirsutum $\times$ thurberi), $6 n$ (G. hirsutum $\times$ raimondii), $6 n$ ( $G$. barbadense $\times$ raimondii), $4 n$ ( $G$. herbaceum $\times$ anomalum), $4 n$ ( $G$. arboreum $\times$ anomalum), $4 n$ ( $G$. arboreum $\times$ herbaceum) and $4 n(G$. thurberi $\times$ raimondii). 
Bud collections were made of both greenhouse and field materials from 1953 to 1956 . The most common fixative was one part chloroform: one part absolute alcohol: one part acetic acid supersaturated with mercuric chloride; other modifications of Carnoy's were also used. Smears were prepared either directly from the fixative after a day at room temperature or else the bud materials were stored under refrigeration at $-10^{\circ} \mathrm{C}$ in the original fixative or in 70 percent alcohol. PMC squashes were made in acetocarmine using one anther per slide. Pollen grains and tetrads were also examined in acetocarmine.

Cells with unexpectedly high or low numbers of chromosomes were called high count or low count cells. The exact number of chromosomes in these cells was often difficult to determine. Therefore, in order to compare the cells in which no definite count could be made with normal cells uncertainties were resolved in the direction of the maximum chromosome number for low count cells and the minimum number for high count cells. Question marks in the table indicate either uncertainties of chromosome numbers or of the types of associations listed there. Cells that might have lost part of their contents through tearing or might have had extra material pressed into them were excluded. No records were kept of the PMC's that appeared empty since it was not always certain whether they actually contained no chromosomes or whether the chromosomes failed to stain. As there were discrepancies in the sampling of the species and the hybrids, the frequencies of the various abnormalities could not be compared and were treated collectively.

\section{Results}

Cytomixis was seen in all meiotic stages and in both hybrids and species of Gossypium. Two typical cytomictic PMC's are shown in early prophase (Fig. 1). The nucleolus and part of the chromosomes from the upper cell can be seen at the edge of the lower cell. This second nucleolus must have entered the lower cell from the upper one since in over 700 normal prophase cells studied there was never more than one nucleolus per cell. In some cases rows of cells were seen to be connected by cytomictic bands like strings of beads. Cytomixis was observed in both squashes and paraffin sections. A diploid $G$. arboreum cell taken from a paraffin section made by Mrs. E. Johansen of this laboratory (Fig. 2) was very similar to Fig. 1 insofar as most of its nucleus had been transported into the next cell. A large clear area can be seen in the region where the nucleus was originally located (all nuclear material was included in this section). Cytoplasmic bands can be seen connecting the two cells; through these the nuclear material had presumably migrated.

Although cytomixis was seen more often in early prophase, it was also 
observed in all other stages. In typical cytomictic MI cells (Fig. 3) some of the chromosomes were stretched and attenuated between the cells while the remainder showed normal bivalent pairing. The cell into which the chromosomes had moved otherwise seemed normal in both chromosome number and appearance. Adjacent cytomictic cells might be in different stages-one might be in $\mathrm{AI}$ while the other might be in MI. Connections were also seen at interphase and even as late as TII (Fig. 5).
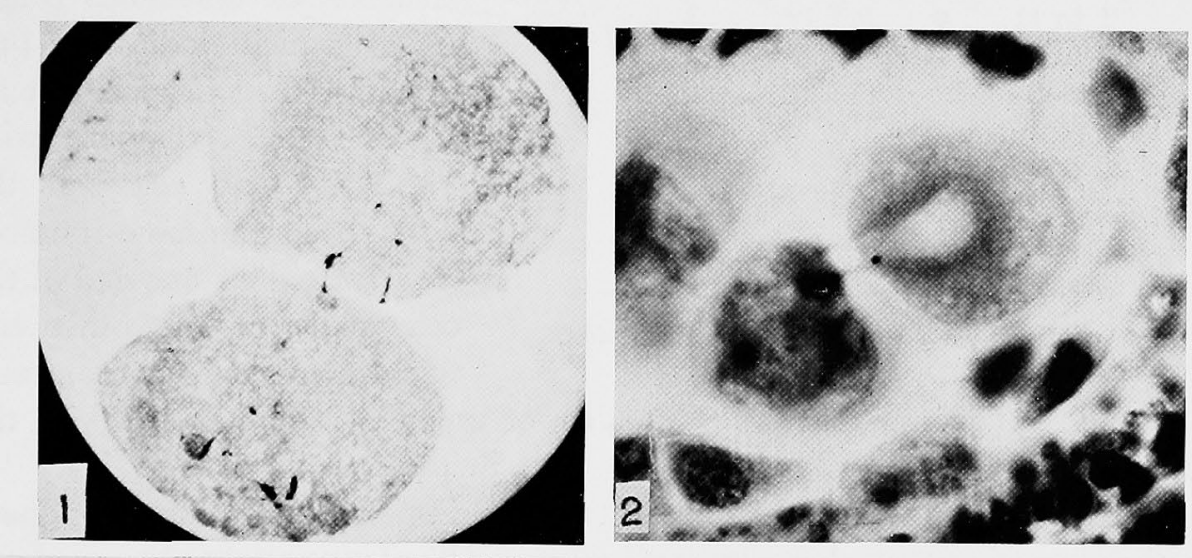

3

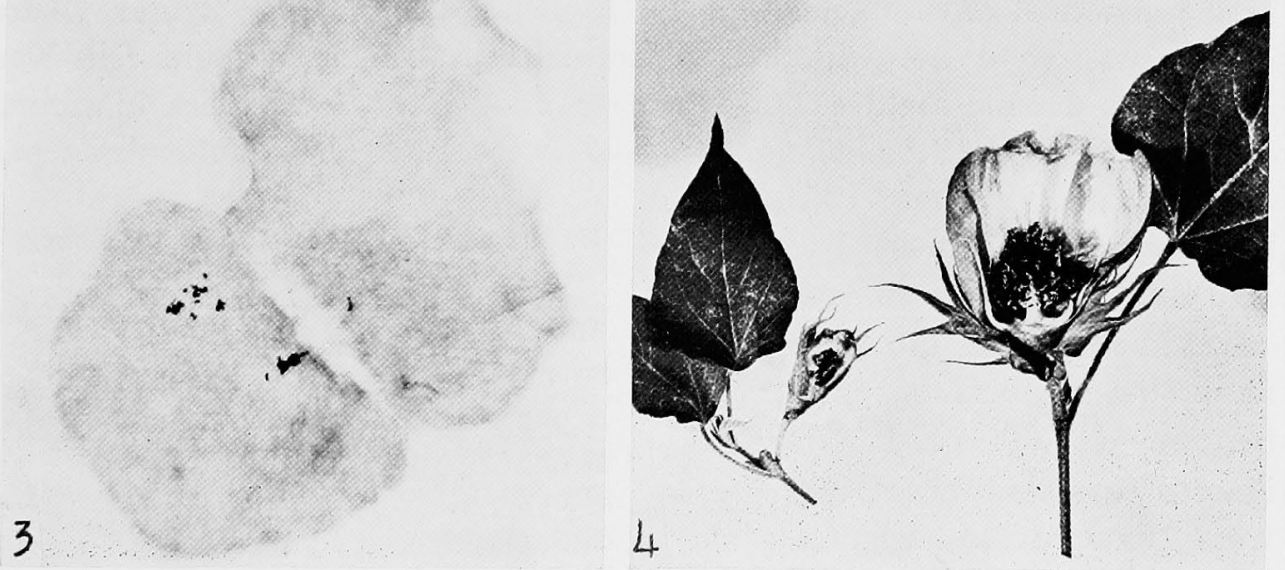

Figs. 1-4. 1, cytomixis in early prophase (squash). Note the location of the nucleoli and the cytoplasmic strands between the two PMC's. G. barbadense $\times$ hirsutum. ca. $120 \times$. 2, paraffin section showing cytomixis. Note cell walls. G. arboreum. ca. $330 \times$. 3, metaphase I in bottom PMC. Top PMC showing cytomixis into lower cell. 4n (G. herbaceum $\times$ anomalum). ca. $120 \times .4$, flower of abnormal (left) and normal (right). 6n (G. hirsutum $\times$ raimondii). Petals have been cut away. The leaf subtending the flower is normally unlobed.

Deviations in chromosome numbers, both higher and lower than normal, were found in the PMC's of almost all of the hybrids studied. For the tetraploid hybrids the numbers ranged from 3 to 85 (Tab. 1); relatively small deviations from the normal chromosome number occurred most fre- 
quently. Low count cells as in Fig. 6 could result from loss of part of the cell; however, cells were seen that had just been squeezed out of their cell walls, and since the PMC's were perfectly round nothing appeared to be

Table 1. Tetraploid PMC's with abnormal numbers of chromosomes

$\begin{array}{cc}\begin{array}{c}\text { Number of } \\ \text { chromosomes }\end{array} & \begin{array}{c}\text { Number of } \\ \text { PMC's }\end{array} \\ 1 \text { to } 11 & 2 \\ 12 \text { to } 21 & 2 \\ 22 \text { to } 31 & 1 \\ 32 \text { to } 41 & 4 \\ 42 \text { to } 51 & 12 \\ 52 & \text { ca. } 700^{*} \\ 53 \text { to } 62 & 19 \\ 63 \text { and over } & 4\end{array}$

* Normal chromosome number for tetraploids.

lost. Outlines of high count cells (Fig. 7) were also regular. In many cases the abnormal cells had attenuated bivalents or univalents (Figs. $6,7)$ which indicated that cytomixis had occurred at an earlier stage (compare with Fig. 1). One cell had the normal chromosome number (52) located at one end of the cell while at the other end thirteen univalents were strung out from the edge. The average number of univalents was higher in the deviating cells of the tetraploids (1.17) than in the normal cells (0.77).

If extra chromosomes were present and could pair during early prophase with the normal set of chromosomes, more multivalents might be expected in the abnormal cells. Yet, in a $G$. hirsutum $\times$ barbadense hybrid where multivalents were not expected in normal cells, abnormal count cells also showed no definite multivalents. Average multivalent frequencies in normal cells of Old World $\times$ anomalum tetraploids were $1.90 \pm 0.10$ multivalents per cell while the deviating cells in the same amphiploids had $1.70 \pm 0.24$ multivalents per cell. In computing the latter mean, the numbers of chromosomes in the cells were ignored since low count cells were thought to counterbalance high count cells.

Hexaploids also had abnormal count PMC's with numbers ranging from 33 to about 99 chromosomes per cell when 78 were expected

Table 2. Hexaploid PMC's with abnormal numbers of chromosomes

\begin{tabular}{cc}
$\begin{array}{c}\text { Number of } \\
\text { chromosomes }\end{array}$ & $\begin{array}{c}\text { Number of } \\
\text { PMC's }\end{array}$ \\
1 to 27 & 0 \\
28 to 37 & 2 \\
38 to 47 & 7 \\
48 to 57 & 5 \\
58 to 67 & 4 \\
68 to 77 & 2 \\
78 & ca. $180^{*}$ \\
79 to 88 & 3 \\
89 and over & 1 \\
\hline Normal chromosome number for hexaploids.
\end{tabular}
(Tab. 2). In contrast to the tetraploids, the modal class contained only onehalf the normal number. However, some cells with almost the correct number may not have been included in the totals as it was not always certain whether these cells were aberrants. Attenuated bivalents and univalents were also observed. Multivalents and univalents were both present 

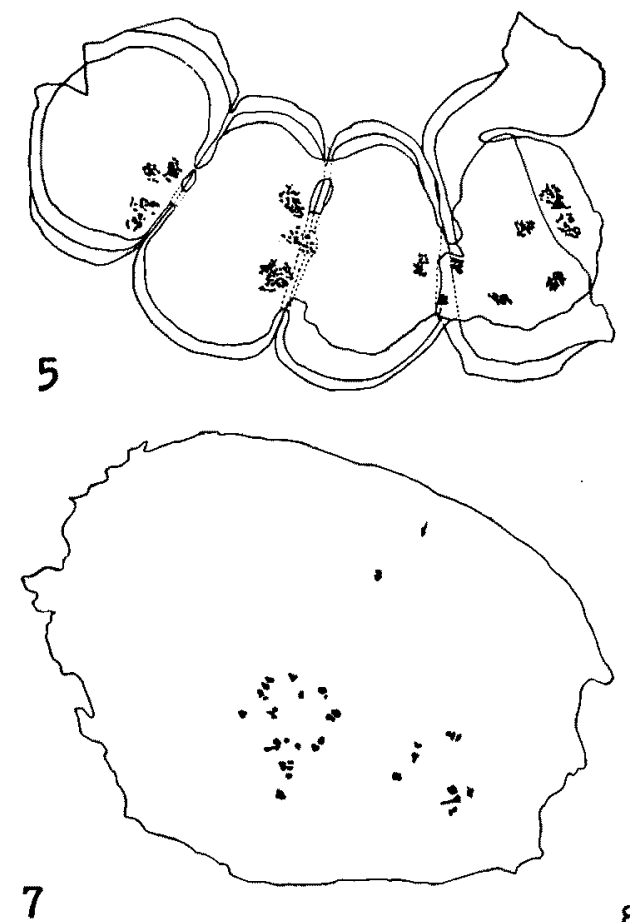

6
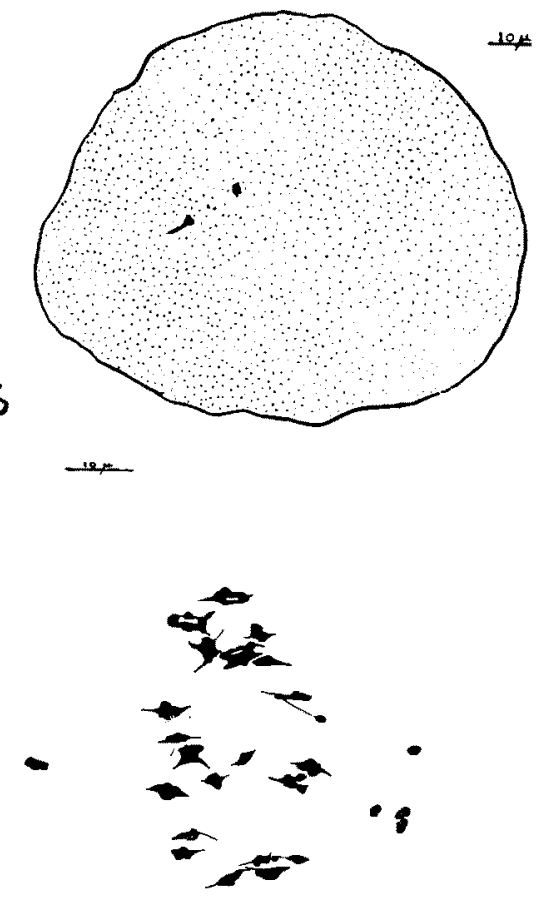

8
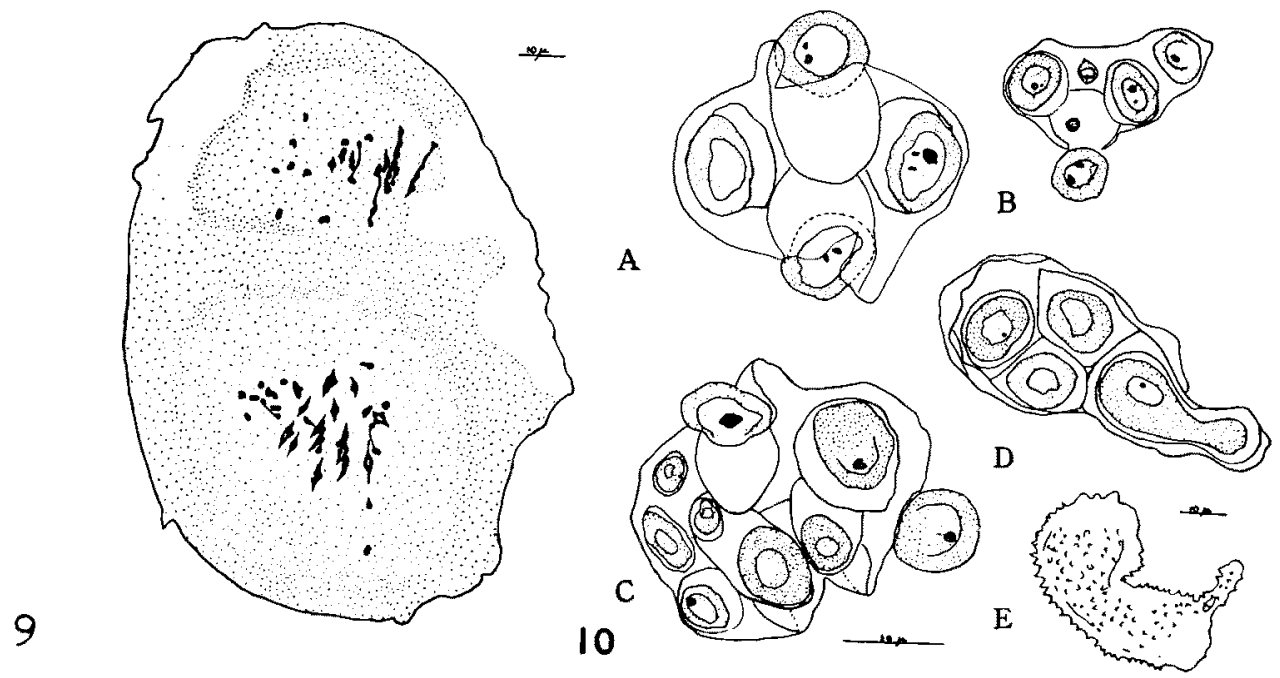

Figs. 5-10. 5, four second telophase cells showing cytomixis. G. hirsutum $\times$ tomentosum. ca. $108 \times .6$, PMC having only one bivalent and probably one attenuated univalent. $G$. barbadense $\times$ hirsutum. 7, diakinesis showing an increased chromosome number $9 \mathrm{I}+30 \mathrm{II}$. Attenuated chromosomes at top and right $G$. barbadense $\times$ hirsutum. ca. $180 \times .8$, reduced number of chromosomes in $6 n$ (G. hirsutum $\times$ raimondii). $6 \mathrm{I}+14 \mathrm{II} ?+2 \mathrm{III}+5 \mathrm{IV}$ ? 9, a PMC with two plates from $6 n$ ( $G$, hirsutum $\times$ thurberi). Top: $9 I+11 I I$; bottom: $13 I+$ 18II. 10, A, normal tetrad in $6 n$ ( $G$. hirsutum $\times$ thurberi). B, small tetrad with two microcytes from same anther as A, C, abnormal "tetrad" with seven large spores and two small ones on the same slide as A and B. D, three normal spores and one large elongated spore. $4 n$ ( $G$. arboreum $\times$ herbaceum). E, abnormal pollen grain. $6 n$ (G. hirsutum $\times$ raimondii). A-D. same magnification. 
in cells with reduced counts (Fig. 8). Frequently, PMC's with reduced counts were clustered in groups. In a single anther of $6 n$ (G. hirsutum $\times$ raimondii) there were seven abnormal cells with the counts ranging from 44 to 62 chromosomes.

Binucleate PMC's were found in both tetraploid and hexaploid Gossypium amphiploids. A typical binucleate MI cell is shown in Fig 9. In this cell two halos can be seen which are present around the nuclei of many normal cells, thus showing that two nuclei were present. Sometimes, the sum of the chromosomes in both nuclei of such a binucleate cell added up to the normal number for the amphiploid (Tab. 3), while in other cases each of

Table 3. Chromosome counts in PMC's with two plates*

\begin{tabular}{|c|c|c|c|c|c|c|c|c|c|c|}
\hline & \multirow{2}{*}{$\begin{array}{l}\text { Number of } \\
\text { chromosomes }\end{array}$} & \multicolumn{4}{|c|}{$\begin{array}{l}\text { First plate } \\
\text { Associations }\end{array}$} & \multirow{2}{*}{$\begin{array}{l}\text { Number of } \\
\text { chromosomes }\end{array}$} & \multicolumn{4}{|c|}{$\begin{array}{l}\text { Second plate } \\
\text { Associations }\end{array}$} \\
\hline & & I & II & III & IV & & I & II & III & IV \\
\hline \multirow[t]{6}{*}{ Hexaploids } & 49 & 13 & 18 & & & 31 & 9 & 11 & & \\
\hline & $34 ?$ & $7 ?$ & 12 & $1 ?$ & & 43 & 7 & 18 & & \\
\hline & $62 ?$ & & & & & $60 ?$ & & & & \\
\hline & 27 & 5 & 11 & & & 51 & 4 & 18 & 1 & $2 ?$ \\
\hline & 42 & 7 & 16 & 1 & & 41 & 3 & 17 & & $1 ?$ \\
\hline & 51 & 1 & 19 & & 3 & 27 & 1 & 11 & & 1 \\
\hline \multirow[t]{5}{*}{ Tetraploids } & 22 & & 11 & & & 52 & & 24 & & 1 ? \\
\hline & $20 ?$ & & & & & $32 ?$ & & & & \\
\hline & $26 ?$ & & $13 ?$ & & & $24 ?$ & & $12 ?$ & & \\
\hline & $52 ?$ & & & & & $52 ?$ & & & & \\
\hline & 12 & & 6 & & & 42 & & $21 ?$ & & \\
\hline
\end{tabular}

* Each row represents a single binucleate cell.

the nuclei contained the full number. Univalents were frequent in these cells with two plates. The spindles of the abnormal cells were sometimes orientated at right angles to each other before the application of pressure to the preparation and thus were not artificially separated or reorientated. These cells could occur singly or in a group. Some binucleate PMC's were seen located next to PMC's that had no chromosomes.

Abnormal tetrads were also observed. One anther contained both a very small tetrad with two microcytes (Fig. 10B) and a sac with many spores of varying sizes (Fig. 10C). A normal tetrad from the same slide is shown in Fig. 10A for comparison. Occasionally, one of the four spores in a tetrad was elongated (Fig. 10D). A pollen grain that could have come from such a tetrad is shown in Fig. 10E.

A morphologically aberrant sector appeared in the top of one plant of $6 n$ (G. hirsutum $\times$ raimondii). The leaves were much smaller and often unlobed. The branches had a tendency to droop, had internodes much closer together than normal, and were crooked. Flowers were smaller, deformed, yet normal in anthocyanin distribution (Fig. 4). The flowers failed to set 
seed and were also male sterile since the anthers failed to dehisce.

Since other morphological changes in cotton had been associated with changes in chromosome numbers (Menzel and Brown 1952; Menzel 1952), the chromosome number of this plant was investigated. Two PMC's from the normal appearing base of the plant had the normal number (78), while metaphase counts from cells at the top of the plant showed that chromosomes had been lost as only 65 or 66 chromosomes were present. The mean number of univalents had increased (from 1.26 to 12.2 ), and the multivalents had decreased (from 5.47 to 1.8). The chromosomes of the two genomes of $G$. hirsutum have been reported as being of different sizes (Brown and Menzel 1952), but the chromosomes of this plant could not be separated into two distinct size groups. Therefore, it was not possible to determine if the lost chromosomes were from one or both genomes.

\section{Discussion}

Four different types of cytological abnormalities have been described here : 1. cytomixis, 2. PMC's with decreased and increased chromosome numbers, 3. binucleate PMC's and 4. somatic loss of chromosomes. The last three types could be the result of the first.

Many of the cell types in which cytomixis has been described, i.e. PMC's, meristematic, tapetal, integumentary, nucellar and ovary cells, have thin walls and/or are united by narrow protoplasmic bands (plasmodesmata). Vaarama (1941), e.g., stated that cytomixis depended on the number of connections and the nature of the cell walls. Cytomixis in cotton appears to be a mechanical process which depends on defective cell wall formation. It is possible that internal or external factors which affect formation of the wall may leave broad connections between two cells through which chromosomes could move, resulting in low and high count cells or binucleate and enucleate ones. If this occurred in PMC's before pachytene, univalents might result; if afterwards, bivalents could be caught between the two cells and become stretched or attenuated. Cytomixis was seen more frequently in prophases than in the later stages. Mendes and Rijo (1951) believed that cytomixis was the result of chromosomal bridge formation caused by chromatin agglutination in the division preceding meiosis. But while this proposal could account for the high proportion of cytomixis at prophase, it cannot explain chromatin strands seen at later stages unless these are remnants of prophase connections. However, the later the meiotic stage in which cytomixis is seen the less likely it is that the earlier connections remain. Multivalent frequencies also tend to contradict the concept of Mendes and Rijo. If additional homologous chromosomes were introduced into a cell before pairing started, they might be expected to pair during early prophase and more multivalents would be observed as a consequence. No increase was observed, 
however, in the number of multivalents as mentioned above. Furthermore, in some PMC's cytomixis must have occurred only after pairing since sometimes whole bivalents were missing or were visible in the chromatin strand.

In Gossypium, at least, cytomixis seems to occur naturally, although it has been claimed to be an artifact in other genera. If it is caused by fixation, mechanical action or abnormal environmental conditions it is hard to see how it could occur in all stages of cell division, in all environments and in both squashes and paraffin sections. That cytomixis is an artifact caused by fixation cannot be completely obviated, of course, until unfixed material is analysed. Linnert (1955) could not find any abnormal tetrads resulting from cytomixis and therefore believed the latter to be an artifact. In the present material, however, abnormal tetrads were seen that would be hard to explain in any other fashion. Small tetrads like the one in Fig. 10B could have originated from a cell with a reduced chromosome count and a tetrad with seven or more spores similar to Fig. 10C from a cell with increased chromosome number or from a binucleate PMC-all of which have been seen in cotton. It may be significant that the small tetrad and the large abnormal tetrad occurred in the same anther. Tetrads like that in Fig. 10D could be caused by an increase in chromatin content in one of the spores through cytomixis which might lead to a pollen grain as in Fig. 10E. It is unlikely that cytomixis is the result of hybridization, polyploidy, or colchicine treatment since it was seen in all the materials examined.

Cytomixis could not only result in high and low count cells but also in binucleate PMC's with either normal or abnormal counts in the two plates. Cases of somatic loss of chromosomes could be the consequence of cytomixis in mitosis, and might explain the presence of mosaic spots in the leaves and petals of the higher hexaploids (Menzel and Brown 1952) ${ }^{1}$.

The evolutionary future of cells with abnormal counts is uncertain as it may be questionable whether they produce viable gametes or zygotes. Probably cells that are enucleate or have large derangements in chromosome numbers will die, while those with minor losses may survive. Sachs (1952) found first generation plants derived from amphiploids in the Triticinae with both lower and higher chromosome numbers than normal. These plants were thought to have originated from gametes which had aberrant cell plates arising through gene-controlled spindle abnormalities. He felt that this mechanism could explain the origin of aneuploid series. However, it is possible that cytomixis could also be responsible there for the production of aberrant gametes which could result in aneuploidy.

1 While this paper was in preparation, Britton and Hull have suggested that the grouping of metaphase chromosomes into two plates may be responsible for the phenomena observed in Gossypium. Britton, D. M. and J. W. Hull. 1957. Mitotic instability in Rubus. J. of Hered. 48: 11-20. 


\section{Summary}

Cytomixis appears to be a natural phenomenon occurring in either mitosis or meiosis between pollen mother cells and other types of cells with thin walls that are joined by cytoplasmic bands. Any external or internal conditions which upset the mechanics of cell wall formation and the rate of division could be a possible cause of cytomixis by leaving cytoplasmic bands through which chromatin movement can occur.

Cytomixis in Gossypium is thought to be responsible for three other types of abnormalities: binucleate cells, pollen mother cells with reduced or increased numbers of chromosomes and somatic loss of chromosomes.

\section{Acknowledgement}

I wish to thank Dr. D. U. Gerstel for his many suggestions and help during the collection and presentation of the data.

\section{Literature cited}

Breslavetz, L. P. 1935. Abnormal development of pollen in different races and grafts of hemp. Genetica 17: 154-169.

Brown, M. S. 1947. A case of spontaneous reduction of chromosome number in somatic tissue of cotton. Am. J. Bot. 34: 384-388.

- 1951. The spontaneous occurrence of amphiploidy in species hybrids of Gossypium. Evolution 5: 25-41.

- and Menzel, M. Y. 1952. Polygenomic hybrids in Gossypium. I. Cytology of hexaploids, pentaploids, and hexaploid combinations. Genetics 37:242.263.

Cooper, D. C. 1952 . The transfer of desoxyribose nucleic acid from the tapetum to the microsporocytes at the onset of meiosis. Am. Nat. 86: 219-229.

Gates, R. R. 1911. Pollen formation in Oenothera gigas. Ann. Bot. 25: 909-940.

Gaul, H. 1954. Uber meiotische Fragment- und Brückenbildung der Bastarde Secale und Triticum $\times$ Agropyrum. Chromosoma 6:314-329.

Gerstel, D. U. 1955. A pollen mother cell of Asiatic cotton with only ten pairs of chromosomes. Cytologia 20: 197-198.

Iyengar, N. K. 1943. Chromosome conjugation in pentaploid cottons. Ind. J. Gen. and P1. Breeding 3: 99-107.

Jacob, K. T. 1941. Certain abnormalities in the root tips of cotton. Current Science 10: 174-175.

Kattermann, G. 1933. Ein Beitrag zur Frage der Dualität der Bestandteile des Bastardkernes. Planta 18: 751-785.

Kihara, H. and F. Lilienfeld. 1934. Kerneinwanderung und Bildung syndiploider Pollenmutterzellen bei dem $F_{1}$ Bastard Triticum aegilopoides $\times$ Aegi'ops squarrosa. Jap. J. Gen. 10: 1-28.

Körnicke, M. 1901. Über Ortsveränderung von Zellkernen. Sitzgsber. Niederrhein. Ges. Natur-u. Heilk. (Bonn.) 1901. pp. 14-25.

Linnert, G. 1955. Cytologische Grundlagen für Sterilitätserscheinungen in der Gattung Salvia. Der Züchter 25: 237-241.

Maheshwari, P. 1950. An introduction to the embryology of angiosperms. McGraw-Hill. pp. 453. 
Mendes, E. J. and L. Rijo. 1951. A new interpretation for "cytomixis.' Portug. Acta Biol. A3: 211-218.

Menzel, M. Y. 1952. Polygenomic hybrids in Gossypium. III. Somatic reduction in a phenotypically-altered branch of a three-species hexaploid. Am. J. Bot 39:625-633.

- and Brown, M. S. 1952. Polygenomic hybrids in Gossypizm. II. Mosaic formation and somatic reduction. Am. J. Bot. 39: 59-69.

Miehe, H. 1901. Uber die Wanderung des pflanzlichen Zellkernes. Flora 88: 105-142.

Nandi, E. K. 1937. Cytological investigations of rice varieties. Cytologia 8: 277-305.

Nybom, N. 1946. Note on a case of sticky chromosomes and cytomixis. Bot. Not. 1946: $122-124$.

Percival, J. 1930. Cytological studies of some hybrids of Aegilops sp. $\times$ wheats, and of some hybrids between different species of Aegilops. J. Gen. 22: 201-278.

Powers, L. 1932. Cytologic and genetic studies of variability of strains of wheat derived from interspecific crosses. J. Agric. Res. 44: 797-831.

Ruttle, M. L. 1928. Chromosome number and morphology in Nicotiana. II. Diploidy and partial diploidy in root tips of Tabacum haploids. Univ. Calif. Publ, in Bot. 11: 213-232.

Sachs, L. 1952. Chromosome mosaics in experimental amphiploids in the Triticinae. Heredity 6: 157-170.

Sarvella, P. 1957. Multivalent formation and genetic segregation in some allopolyploid Gossypium hybrids. Submitted.

Stebbins, G. L. Jr. 1932. Cytology of Antennaria. II. Parthenogenetic species. Bot. Gaz. 94: $322-345$.

Tischler, G. 1951. Handbuch der Pflanzenanatomie Bd II. Gebrüder Borntraeger. BerlinNikolassee. pp. 1040.

Vaarama, A. 1941. Beobachtungen über die Cytomixis in meiotischen Pollenmutterzellen von Sagittaria natans Pall. Ann. Acad. Sci. Fenn. A-IV 4:3-20.

Woodworth, R. H. 1929. Cytological studies in the Betulaceae. II. Corylus and Alnus. Bot. Gaz. 88: 383-399.

Yamashita, K. 1937. Uber eine diplo-tetraploide Chimäre bei Triticum. Cytologia, Fujii jub. vol. $1062-1069$.

Youngman, W. 1931. Studies in the cytology of the Hibisceae. III. A study of the prophase of the nucleus of the pollen mother-cell of Thespesia populnea. Ann. Bot. 45: $211-227$. 